\title{
Evaluating and Zoning Flood Susceptibility Using Curve Number (CN) Logistic and Hydrological Regression Model (Case Study of Kalateh Qanbar Drainage Basin, Nishabur)
}

Mohammad Ali Zangeneh Asadi ${ }^{1}$

Associate Professor of Geomorphology, Faculty of Geography and Environmental Sciences, Department of Geomorphology, Hakim Sabzevari University, Sabzevar, Iran

Abolghasem Amirahmadi ${ }^{2}$

Professor of Geomorphology, Faculty of Geography and Environmental Sciences, Department of Geomorphology, Hakim Sabzevari University, Sabzevar, Iran

Leila Goli Mokhtari ${ }^{3}$

Assistant Professor of Geomorphology, Faculty of Geography and Environmental Sciences, Department of Geomorphology, Hakim Sabzevari University, Sabzevar, Iran

Mahnaz Nemi Tabar ${ }^{4}$

Ph.D student of Geomorphology, Faculty of Geography and Environmental Sciences, Department of Geomorphology, Hakim Sabzevari University, Sabzevar, Iran

\section{Abstract}

Spatial evaluation of flood-prone areas at the drainage basins is one of the basic strategies in the field of flood risk management. The present study aims to investigate the efficiency of the $\mathrm{CN}$ logistic and hydrological regression model for predicting and zoning floods. In the first stage, 13 runoff parameters, hydrologic soil groups (HSGs), slope, lithology, drainage density (DD), land curvature, elevation, distance to waterways/rivers, topographic wetness index (TWI), stream power index (SPI), rainfall, land use, and NDVI were employed. In the SCS-CN model of the drainage basin, the infiltration rate (S) and runoff amount (Q) were determined. The weights of the used layers were weighted by the AHP. Also, a flood zoning map of the drainage basin with different $5,15,25$, and 50 year return periods was drawn by applying the weights of the layers. To ensure the accuracy of the zoning map with the logistic regression model, the ROC curve, and the area below the curve were used. The results showed that for the prediction rate, the AUC is $0.81 \%$, indicating that the model has acceptable accuracy. The most important factors affecting flood are geological index; distance to waterways/rivers; and NDVI in the logistic regression model, and slope, DD, rainfall, and land use in the SCS-CN model respectively. 30 to $46 \%$ of the drainage basin area during 5 to 50 year periods has moderate flood potential, and 28 to $34 \%$ has high potential.

Keywords: flood proneness, zoning, $\mathrm{CN}$ hydrologic model, curve number $(\mathrm{CN})$, logistic regression.

\subsection{Introduction}

Water is a vital part of human life. Since the genesis of man on earth, drought and floods have affected his activities around the world. Floodplains are a key ecological part in arid and semi-arid regions that with

\footnotetext{
${ }^{1}$ Ma.zanganehasadi@hsu.ac.ir

ªmirahmadi@hsu.ac.ir

32.mokhtari@hsu.ac.ir

${ }^{4}$ mahnaznaemi70@gmail.com

${ }^{1}$ Department of Physical Geography, Faculty of Geography and Environmental Science, Hakim Sabzevari University, Sabzevar, Iran
} 
fertile soil and water flow, are considered as an important agricultural hub as well as a human habitation. However, what always threatens these ecologically susceptible areas is the occasional river floods, causing irreparable financial and human damage (Roustaei et al., 2020: 29). Flood is the most common natural hazard in the world (accounting for about $47 \%$ of the hazards in the world), affecting many world people every year (Yari et al., 2019). There is a trend of increasing floods in the world because of climate change, changes in rainfall patterns, and rises in sea levels in the future. Besides, population growth and urban development, and human settlements have caused floods to become a threat to human life (Fallah et al., 2019). Estimating runoff volumes due to rainfall and applying methods for collecting and controlling surface water is of great significance both in terms of water supply and flood prevention (Mollazehi et al., 2020: 242). Many factors such as climatic, drainage basin, and human ones are involved in causing floods. Among the climatic factors were the dryness of the region, heavy rainfall, and relatively short duration. The most significant factors in drainage basins can be the geological status, vegetation, area of drainage basins, their shapes and forms, slope, and the focal points (Esfandiari Darabad, 2019: 156). In the field of flood zoning, various researches have been done inside and outside the country, some of which are mentioned. in a study entitled " evaluation of the impact of river bed land-use change on amount and severity of floods (case study: Ardak River)", Mirghasemi et al. (2017) employed the HEC-HMS model and obtained the results that by changing the riverbed to horticultural and agricultural land uses, maximum flood discharge and the runoff volume decrease. Therefore, due to the change of river bed land use, this reduction rate decreases as the flood return period increases so that for floods with a 25 year return period, maximum flood discharge and runoff volume show $3.3 \%$ and $2.6 \%$ reduction, respectively. In their study, "prioritization of Sardab-Rood watershed from flooding viewpoint using the SWAT model" Talebi et al. (2017) concluded that the CN was recognized as the most important parameter and as a result, the fixed parameters of groundwater discharge (ALPHA-BF), groundwater latency (GW-DELAY) and the minimum amount of water storage required to generate the base flow (GWQMN) are more susceptible, respectively. Beitollahpour et al. (2015) investigated the feasibility of using satellite images to determine the bed boundary of rivers. In their study, integration of HEC-RAS, ArcGIS, and HEC-GeoRAS was employed to determine the bedrock of the Gabrik River in Hormozgan province and also to prepare a flood zoning map. The results show that satellite images can estimate riverbeds properly. Sharifi Pichun et al. (2015) evaluated and analyzed the spatial flooding of the Qarasu River using fuzzy logic in GIS. Their findings show that in the study basin, most of the membership functions between the effective parameters in flooding are linear and direct. Gorji et al. (2017) studied the flood zoning of the Nekarud basin using the SCS-CN model. Their study indicated that the simultaneous application of RS and GIS, as well as the SCS-CN model can be useful in preparing flood zoning maps. Rahimzadeh et al. (2019) performed the simulation process of the flood zone at a distance of $10 \mathrm{~km}$ to Gorganrud River by two one-dimensional hydraulic models HECRAS and LISFLOOD-FP 2D models. The results showed that the LISFLOOD-FP 2D flood inundation model presented slightly better results than the one-dimensional HEC-RAS model. Jia et al. (2019) addressed flood risk zoning using a hybrid model of the hierarchical analysis process and fuzzy logic in Henan Province, China. The results show the high efficiency of the model used in flood risk zoning. Accordingly, the vulnerability to flooding risk in the eastern parts of the study province is higher than in the western parts. Pratyasha Gina et al. (2016) simulated flood risk in areas with data and information shortages. They stated that the digital elevation model plays an important role in flood modeling. Aziza Abbas et al. (2014) employed the RS technique and SCS-CN model to investigate the effect of spatial changes in the city on runoff production and flooding in Kuala Lumpur, Malaysia. The results showed that there is a significant relationship between spatial patterns of urban growth and runoff height. Tang et al. (2018) in the evaluation of flood susceptible areas using GIS-MCDA multi-criteria decision analysis using Monte Carlo simulations, probabilistic methods, and weighted average (OWA) in Guocheng, central China. These results showed that geomorphological and hydro-metrological factors are effective in the occurrence 
of floods and the weight of the criteria has the most change in the model results and can provide a logical, objective tool for assessing flood susceptibility. Reisenbüchler et al. (2019) investigated the relationship between flood and the morphology of the Salzach River and concluded that the TELEMAC-MASCARET hydro-morphological model indicates flood inundation and can provide reliable predictions. More to be used. Mohtar et al. (2020) in a study in Kuala Lumpur, Malaysia, concluded that the 50-ARI precipitation model is highly accurate in identifying flood-prone areas by providing a comprehensive focus map, floodprone color maps. For integrated flood management, the present study seeks to predict and zone flood risk in Kalateh-ye Qanbar Drainage Basin of Khorasan Razavi province using the two CN logistic and hydrological regression models.

\subsubsection{The study area}

Covering Zebarkhan and Mian-Jolgeh counties at "53 58 58E latitude and" 53 49 35N longitude, Kalatehye Qanbar Drainage Basin with an area of 2422.2 hectares is located in the southeast of Nishabur Township, Khorasan Razavi province in northeastern Iran. Also, a part of the basin is located in the north of Torbat Heydariyeh city and Kadkan County. The study area is adjacent to the villages of Abdolabad and Homayi westerly, the villages of Ishaqabad and Janatabad northerly, and Islamabad village northeasterly (Figure 1).

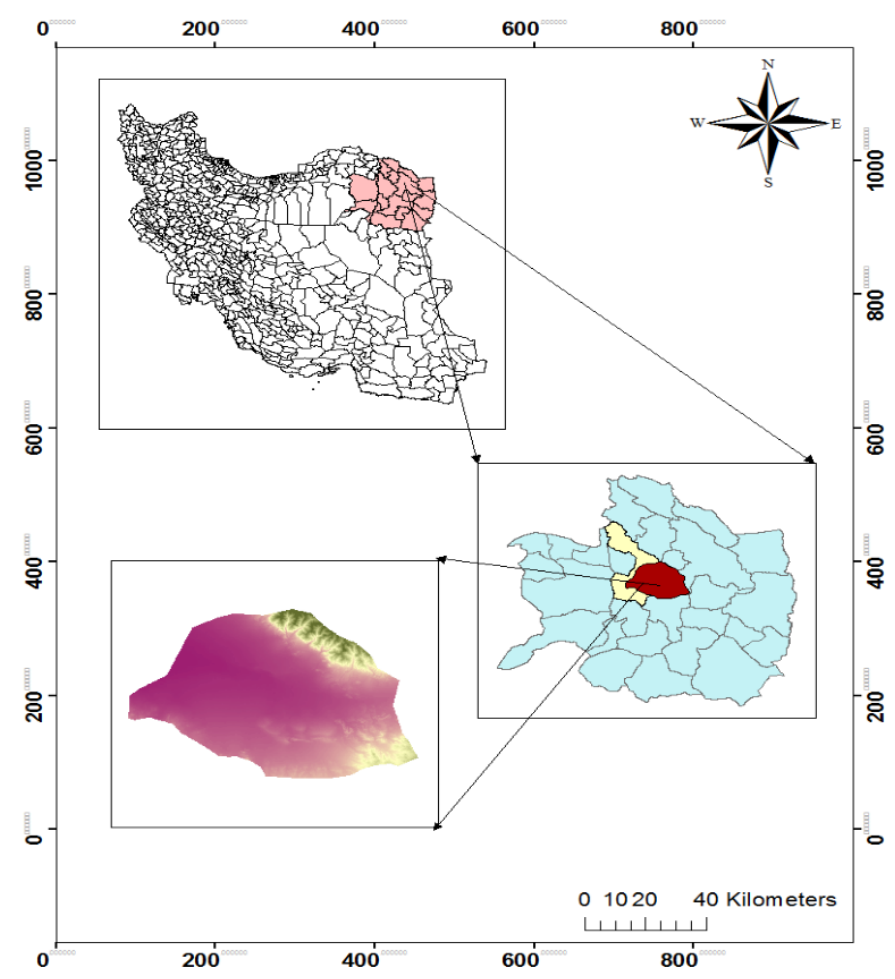

Fig. A.1: Location of the study area

\subsection{Materials and methods}

To investigate the flood situation in the study area, using the digital elevation model, the basin area was determined digitally. This map is the basis for preparing a slope map that has been obtained to integrate with other layers. In this research, a DEM with a pixel size of 10 meters was used. Then lithological map was drawn using a 1:100000 geological map. Since soil properties affect the evolution and formation of runoff, it is necessary to determine the hydrological group of the soil to check the $\mathrm{CN}$ condition. To determine the hydrological group of soil in the SCS-CN model, it is necessary to prepare a land-use map. 
Landsat 8 satellite images of 2018 have been used to prepare the land use map. Equation 1 was used to prepare the topographic index (TWI) and the waterway power index (SPI) map was prepared from equation 2. To prepare the rainfall layer from 20-year data (1999-2019) of Nishabur, Bakavol, Sanobar, Malek Abad, Bar, Farhadgerd, Dahanehshoor, Alang Asadi, Qadirabad, Ardak, Torgh Dam, Iraj Abad, Eishabad, Taghoon, Andarab Zarandeh, Beyut, Fadiyeh, Namagh, Hosseinabad Jangal, Rouhabad, and Dizbad Bala rain-gauging stations were used. Then the kriging spatial interpolation method was employed to draw a rainfall map due to having the lowest amount of RMSE and MEA errors. Equation 3 was used to prepare the vegetation density layer. The map of maximum penetration in the area is prepared using Equation 4. This layer shows the amount of rain that penetrates the ground. In the next step, precipitation zones with 5 , 15,25 , and 50 year return periods were prepared from data related to daily maximum precipitation. To prepare this layer, the statistics of 29 meteorological stations in the region with a 20 -year common statistical period were used. After performing the relevant tests concerning the homogeneity and adequacy of the data, the amount of precipitation for the desired return periods has been prepared using the Gamble distribution. They were then interpolated using the IDW model. Since the minimum error in the rain data was quadratic; equation 5 was used for drawing the runoff layer map.

Equation 1:

$\mathrm{TWI}=\mathrm{LN}\left(\frac{\mathrm{AS}}{\operatorname{Tan} \beta}\right)$

Where As is the specific surface of the basin, and $\beta$ is the slope of the land by degree.

Equation 2:

$\mathrm{SPI}=\mathrm{AsTan} \beta$

Equation 3:

$\mathrm{NDVI}=(\mathrm{NIR}-(\mathrm{NIR}+\mathrm{VIS})$

Where VIS and NIR are measurements of the return of the visible and near-infrared light spectrum respectively.

Equation 4:

$\mathrm{S}=25.4\left(\frac{1000}{\mathrm{CN}}-10\right)$

Equation 5:

$$
\mathrm{Q}=\left(\frac{\mathrm{P}-2 \mathrm{~S}}{(\mathrm{P}+8 \mathrm{~S})}\right)
$$

Where $\mathrm{P}$ represents precipitation in millimeters, $\mathrm{S}$ is the amount of infiltration in millimeters, and $\mathrm{Q}$ represents the amount of runoff in millimeters.

\subsubsection{Logistic regression model}

Logistic regression is a multivariate statistical analysis that considers several physical parameters that may affect the probability of flooding (Shirzadi et al., 2012). Thus, 70\% of the flood training points are included in the model as dependent variables and the factors affecting the flood as independent variables (Homser et al., 2000). The coefficients of the logistic regression model are estimated by the maximum likelihood method, which is used for the final map in GIS. Then SPSS16 software was used to run the regression model by Roths. In this method, all factors are entered into the model without deletion. One of the advantages of the logistic regression model is that the data do not need to be normally distributed and the influencing factors can be continuous or discrete. The purpose of logistic regression is to determine an appropriate model to define the relationship between the dependent variable and the factors affecting the flood to generate coefficients for each variable (Lee et al. 2, 2007). Logistic regression to predict the presence or absence of complications as zero and one relies on the values of predictor variables. Quantitatively, the relationship between the event and its dependence on several variables is expressed as Equation 6. 
Equation 6:

$\mathrm{P}($ event $)=\frac{\mathrm{ez}}{(1+\mathrm{ez})}$

$P($ event $)$ is the probability of a flood. As the value of $\mathrm{z}$ varies from $-\infty$ to $+\infty$, the probability of occurrence varies from 0 to $1 . Z$ is the linear combination function of the effective factors that represent the linear relationship and $b_{0}$ is the intercept of the model.

Equation 7:

$\mathrm{Z}=\mathrm{b}_{0}+\mathrm{b}_{1} \mathrm{x}_{1}+\mathrm{b}_{2} \mathrm{x}_{2} \ldots+\mathrm{b}_{\mathrm{n}} \mathrm{x}_{\mathrm{n}}$

Equation 8 is the general equation of logistic regression.

Equation 8:

$\mathrm{y}=\log \operatorname{it}(\mathrm{p})=\operatorname{in}\left(\frac{p}{1-p}\right)=\mathrm{b}_{0} \mathrm{~b}_{1} \mathrm{x}_{1}+\mathrm{b}_{2} \mathrm{x}_{2} \ldots+\mathrm{b}_{\mathrm{n}} \mathrm{x}_{\mathrm{n}}$

$Y$ is the probability of flooding, bn $(\mathrm{i}=0,1 \ldots \mathrm{n})$ is the estimated coefficients of the sample data, $\mathrm{n}$ is the number of independent variables and $x n(i=0,1 \ldots n)$ represents the independent variables. Positive coefficients indicate a positive correlation between effective factors and dependent variables, and negative coefficients indicate the opposite effect. Since the relationship between the independent variables and the probability of occurrence is nonlinear, an iterative algorithm is necessary to estimate the parameter. Then the ROC curve method and the area under its AUC are used for evaluation. If the AUC is 1, it indicates the complete accuracy of the prediction.

\subsubsection{Determining the $\mathrm{CN}$}

The $\mathrm{CN}$ is a dimensionless parameter that is used in the SCS model to determine the initial loss parameter as well as the latency of the domain. This number is used to determine the $\mathrm{CN}$ of the basin and to overlap different layers such as land use and HSGs. After identifying the HSGs of the basin soil to determine the $\mathrm{CN}$ of the basin using the digital elevation model of land use map along with the soil map of the basin and creating its layer in Arc GIS environment and overlapping these layers, $\mathrm{CN}$ for soil sets and vegetation is estimated based on the previous average curve number of mode II (Rustaei et al., 2017). The hypothetical mean method is used to obtain the curve number of the sub-basins. For this purpose, soil and land use maps are overlapped and homogeneous units are identified. Then specify the number of curves in each unit and multiply by the area covered. If the sum of the multiplications is divided by the total area of the basin, the average $\mathrm{CN}$ is obtained.

\subsection{Discussion}

\subsubsection{Slope}

Land slope determines the manner and amount of flow and speed of water movement. In this way, in lands with a steep slope, under the influence of gravity, water has a high velocity (Saraskanrood et al., 2015: 237). In the study area, the average slope is 30 degrees and in some mountainous areas, the slope is above 45 degrees. At a slope above $45^{\circ}$, the water velocity increases and reaches the end of the basin faster and accumulates faster, resulting in a sharper hydrographic peak flow (Figure 2). 


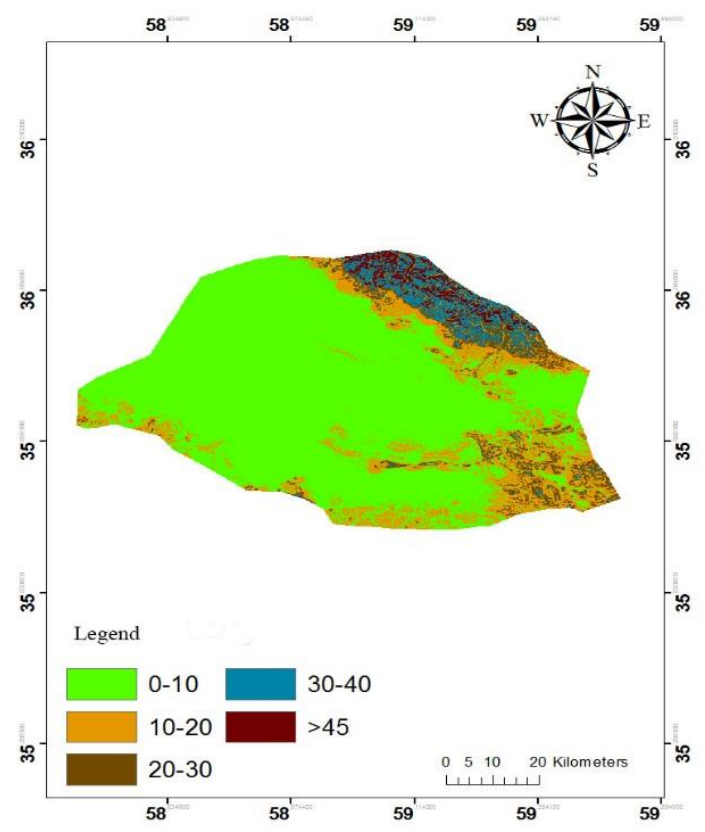

Fig. A.2: Slope

\subsubsection{Drainage density}

The state of the drainage network plays a major role in the occurrence of floods. The flow in waterways is faster than the surface flow; therefore, the higher the drainage density, the faster the runoff accumulation speed and the steeper the hydrograph ascent curve. By examining the relationship between drainage density and coefficient of 0.876 with the highest and coefficient of 0.103 with the lowest value has the greatest effect on flood occurrence (Figure 3). 


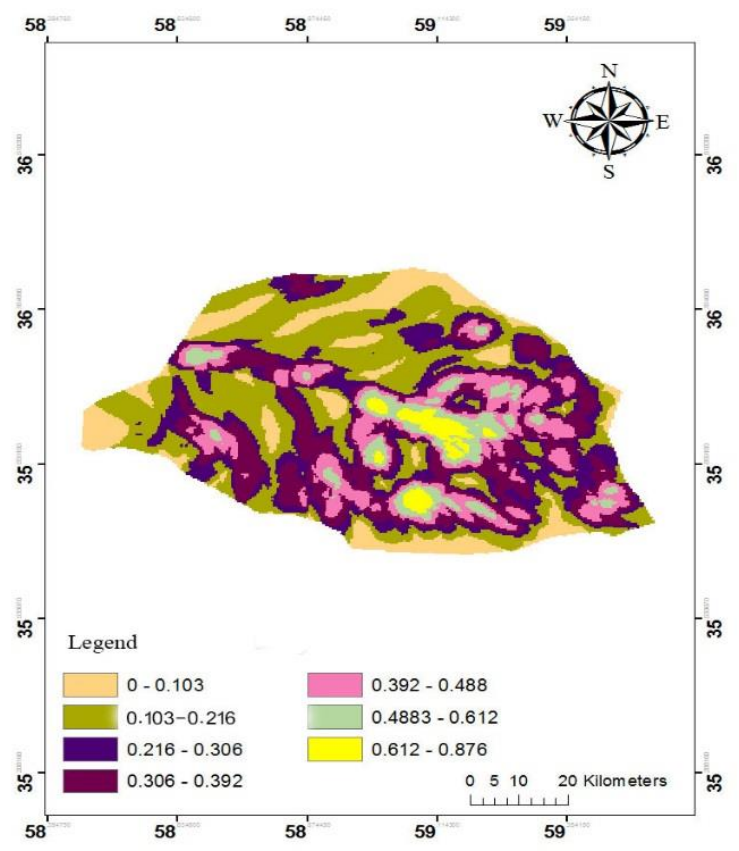

Fig. A.3: Drainage density

\subsubsection{Vegetation density}

In the study area, some central, as well as western and southwestern parts of the basin, have dense vegetation areas. As a result, the rate of water infiltration and runoff formation is reduced. In the northern and eastern parts, the vegetation area is weak and consequently, the rate of infiltration is low and increases the risk of floods (Figure 4). 


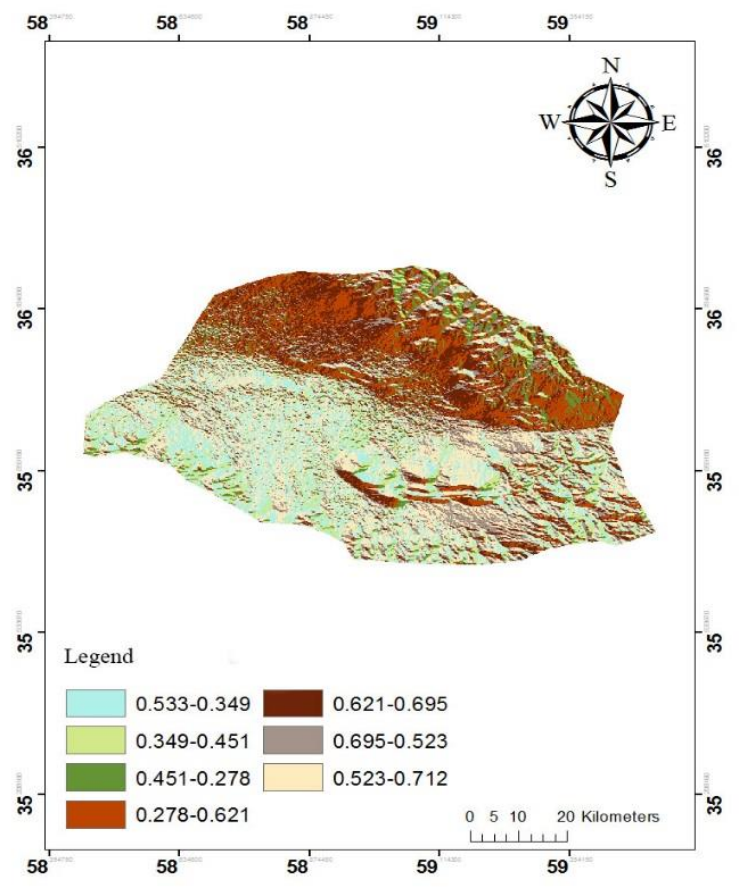

Fig. A.4: NDVI

\subsubsection{Lithology}

In some cases, lithology is considered the most important factor in controlling the flooding process. Changes in lithological properties due to changes in the permeability and strength of rocks, affect the intensity and distribution of floods (Fani et al.: 2017). In the study area, the siltstone unit of susceptibility to erosion or its erodibility and sedimentation is also high so that superficial and grooved erosion forms are seen on them. On their surface, there are fine-grained pink soils with considerable thickness. This unit salinizes surface water (floods) and groundwater. The resulting soil is to some extent brackish. The old alluvial barracks unit has a high potential for erosion and sedimentation. However, because their soils are very sloping, floods do not have much evaporative and erosive energy to reach them and no lateral erosion is seen in them. The young fluvial terrace unit has a high erodibility due to the high density of new waterways in the study area (Figure 5). 


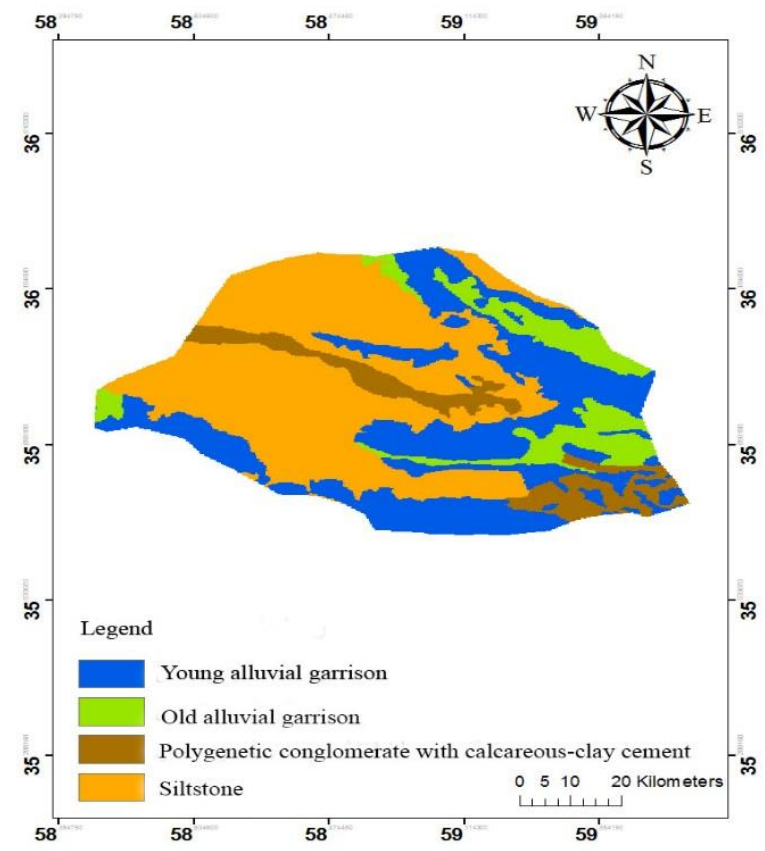

Fig. A.5: Lithology

\subsubsection{Land curvature}

Slope curvature indicates the topographic shape. Positive concavity indicates the surface at which the pixels are convex, negative concavity indicates the surface at which the pixels are concave, and zero means the surface is non-sloping and flat (Lee, 2004). Flatlands have the greatest impact on floods and convex slopes have the least impact on floods. In concave slopes, flooding is moderately effective (Figure 6).

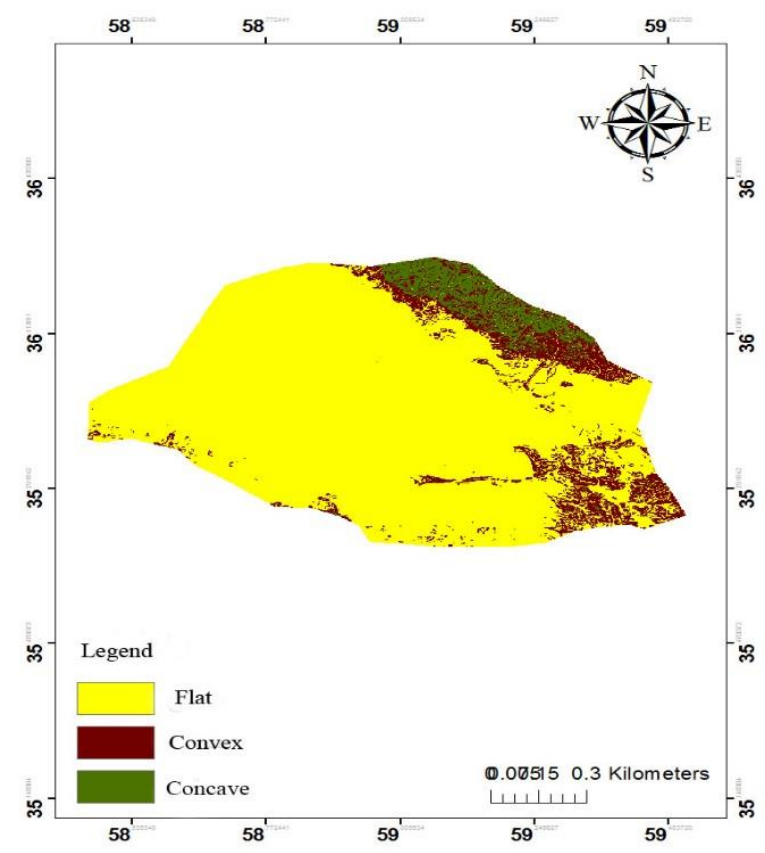


Fig. A.6: Land curvature

\subsubsection{Elevation}

The topographic features of an area play an essential role in controlling the mechanism of flood occurrence. As the energy of flood flow as well as its distribution in areas with different levels and geomorphological shapes will not be the same (Green et al., 2014). In the study area, the highest occurrence of floods occurred at an altitude of 1500-1000 meters (Figure 7).

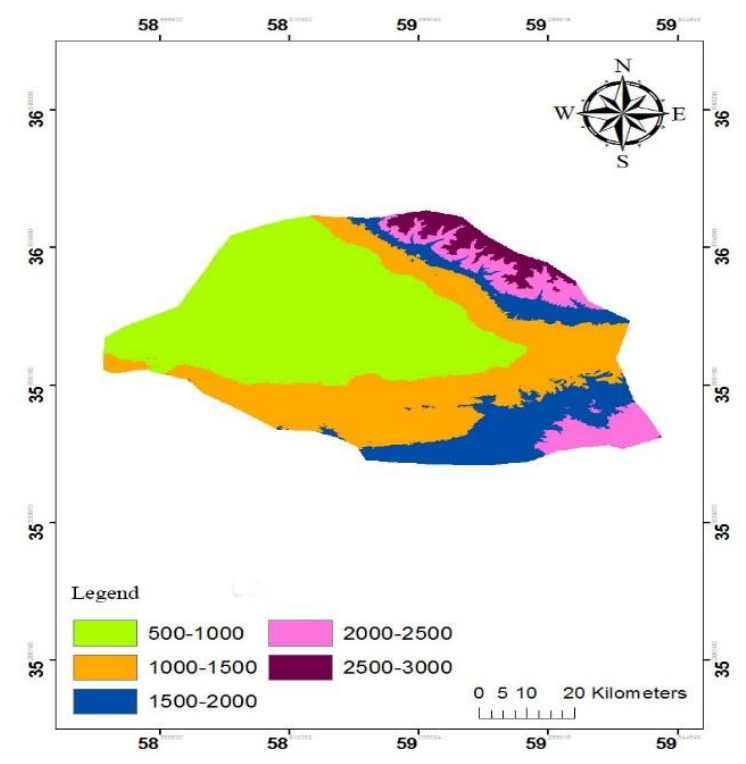

Fig. A.7: Elevation

\subsubsection{Distance to rivers}

Waterways are the primary bedrock of floods so that at close distances the probability of floods is high and at longer distances, the role of waterways in floods is less (Wang et al., 2015). In the study area, most floods occurred at a distance of 0-500 m (Figure 8). 


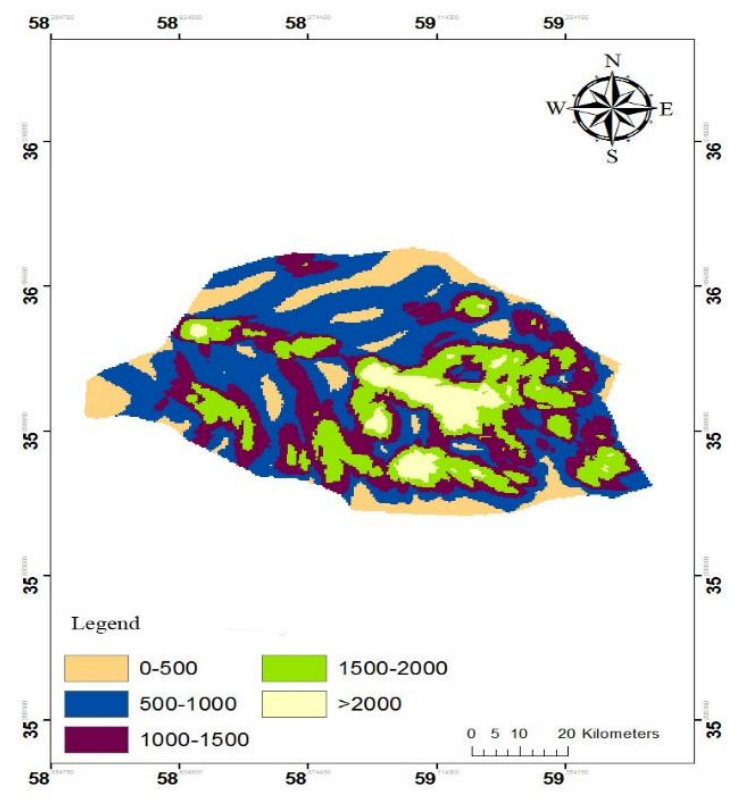

Fig. A.8: Distance to rivers

\subsubsection{Topographic Wetness Index (TWI)}

The TWI is a secondary topographic feature that shows the spatial distribution of moisture conditions (Razavi Termeh et al., 2017). In the study area, class 294/8-395/9 has the greatest impact on the occurrence of floods in the area (Figure 9).

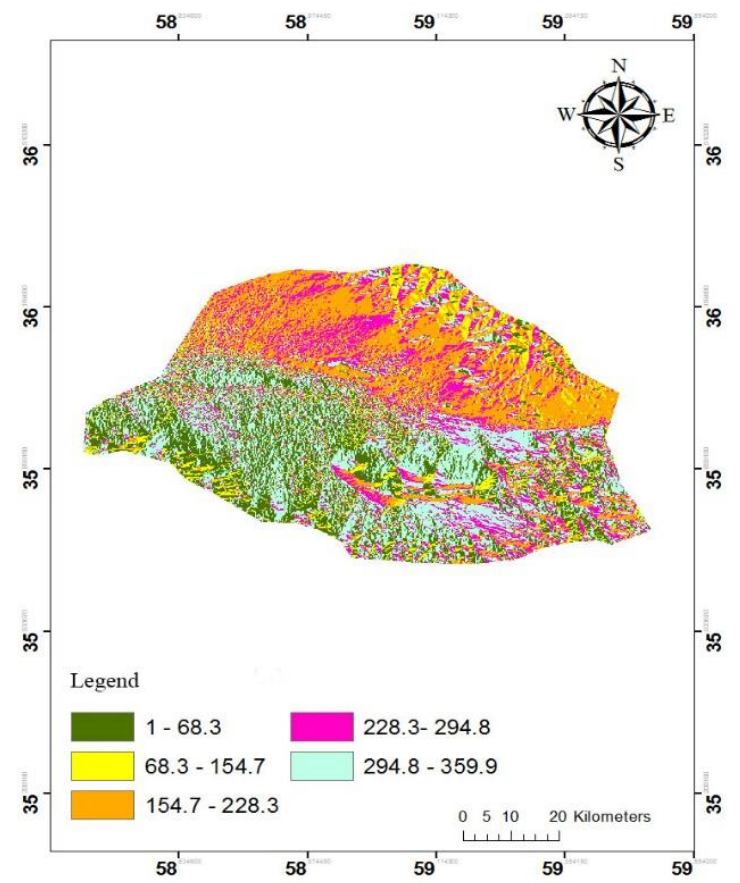

Fig. A.9: Topographic Wetness 


\subsubsection{Stream Power Index (SPI)}

The SPI indicates the erosion capacity of the stream, which is directly related to the degree of slope and area of the watershed. Therefore, when the surface flow velocity increases, the SPI increases as well (Pour Taghi et al., 2014). In the study area, class 327/4-395/99 has the greatest effect on the occurrence of floods (Figure 10).

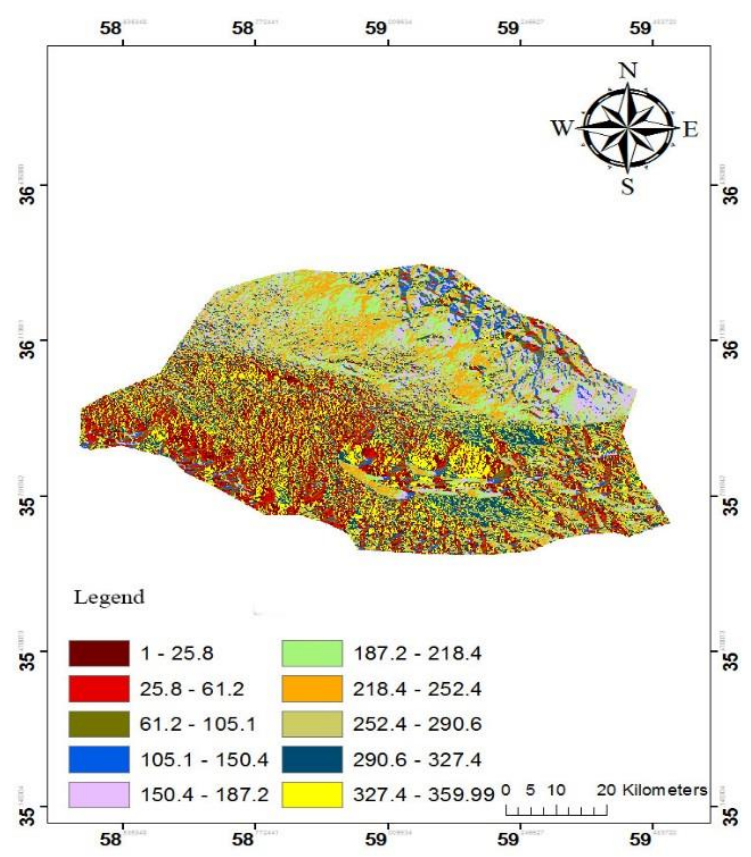

Fig. A.10: Stream Power

\subsubsection{Rainfall}

Rainfall can be considered as the most important factor that is directly involved in the hydrological cycle. Certainly not flooding if it does not rain. In the field of study, spring is the season of sudden rains, snowmelt, river floods, and severe floods in the region. Areas with more rainfall are more effective in the occurrence of floods. In the study area, more than $220 \mathrm{~mm}$ of rainfall has the greatest impact on the occurrence of floods (Figure 11). 


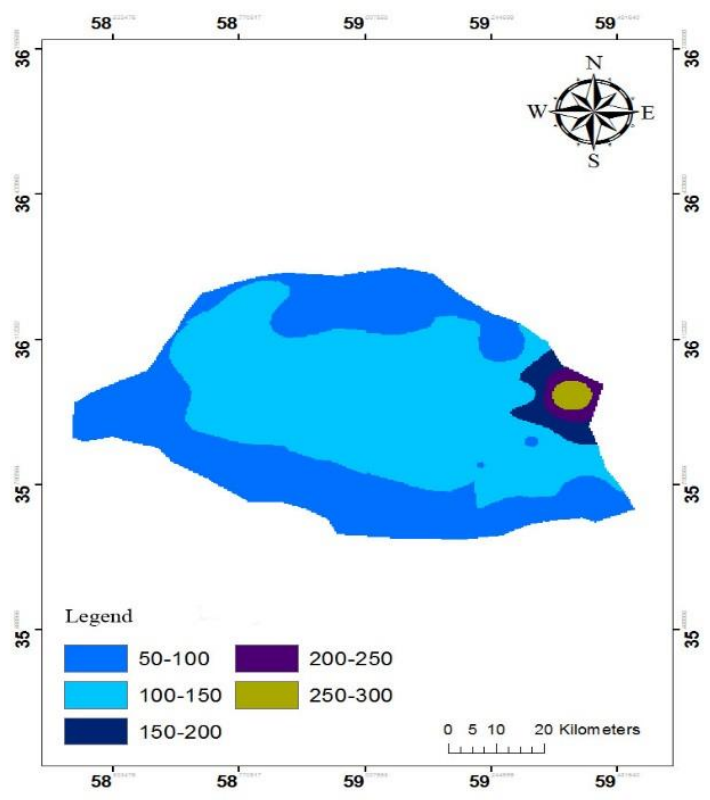

Fig. A.11: Rainfall

\subsubsection{Land use}

Land use and how human activities are distributed are influential factors in the results of spatial analysis. Rangeland land use in the mountains has the greatest impact on the occurrence of floods in the study area (Figure 12). Areas with less vegetation are prone to flooding.

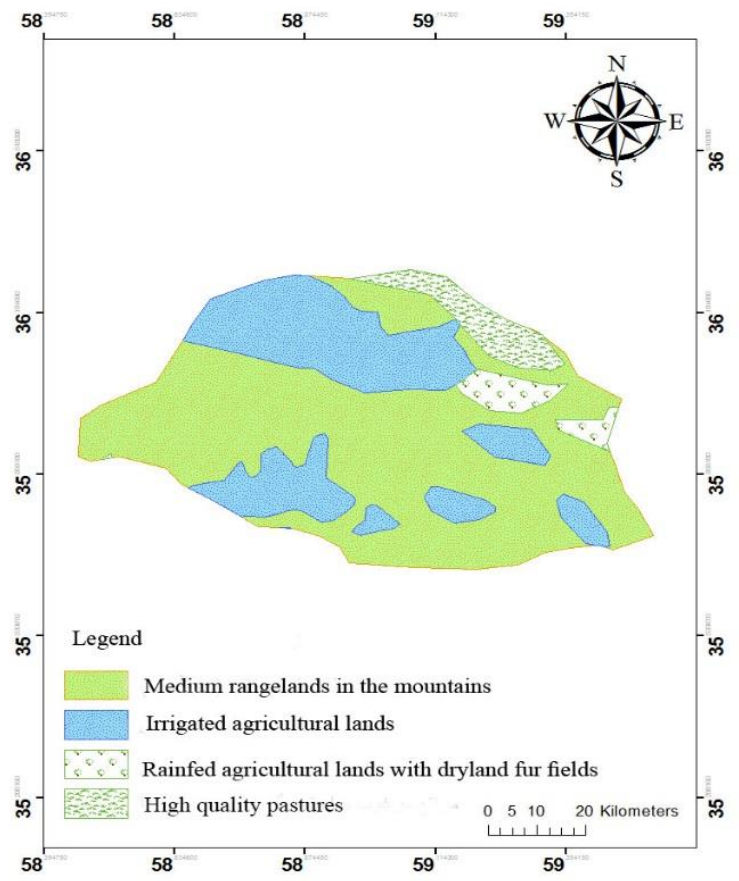

Fig. A.12: Land use 


\subsubsection{Runoff}

The SCS-CN equation has been used to estimate surface runoff at 5, 15, 25, and 50 years. This $\mathrm{CN}$ parameter plays an important role in estimating runoff and flood. To determine the $\mathrm{CN}$, the soil of the area, land use, vegetation density, and rainfall of the basin were used (Figures 13, 14, 15, and 16).

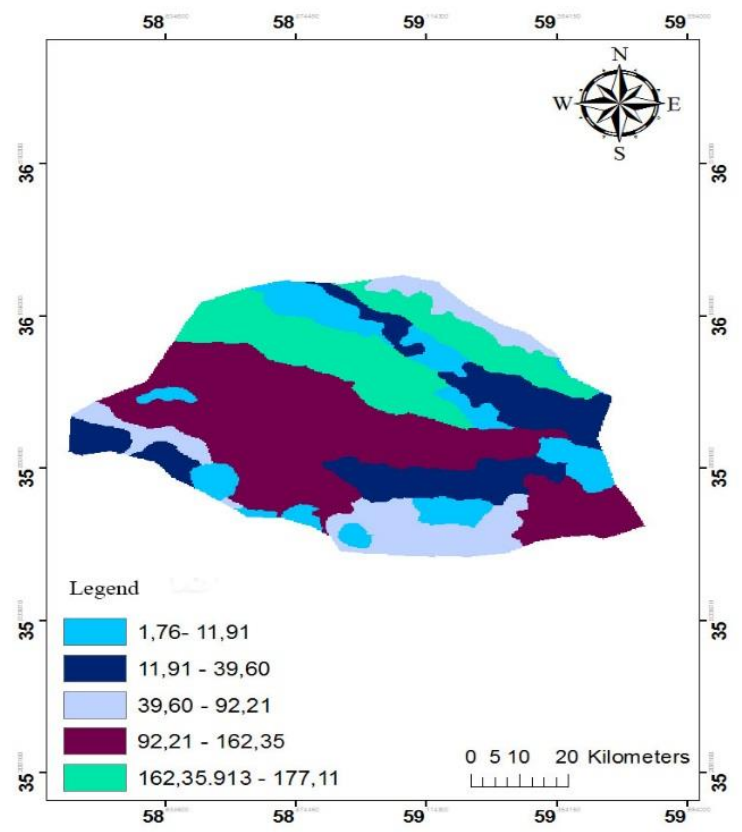

Fig. A.13: Maximum daily Runoff with a return period of 5 years

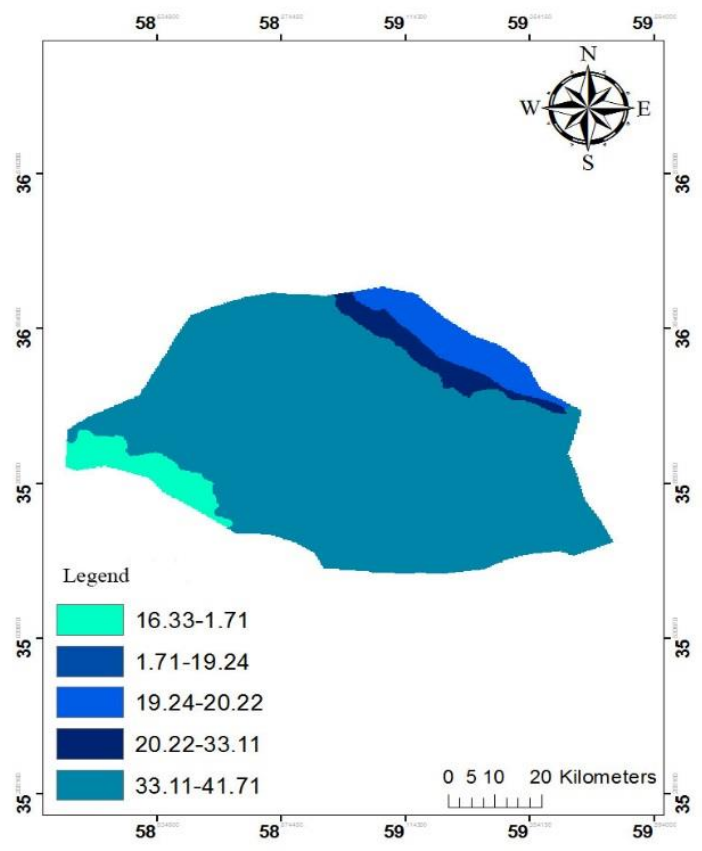

Fig. A.14: Maximum daily Runoff with a return period of 15 years 


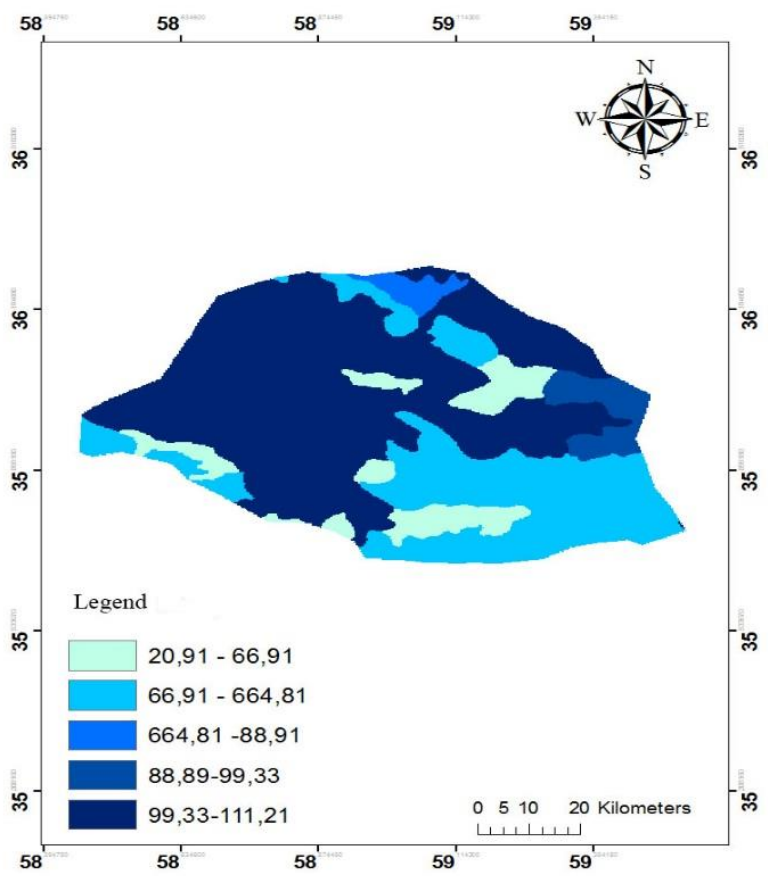

Fig. A.15: Maximum daily Runoff with a return of 25 years

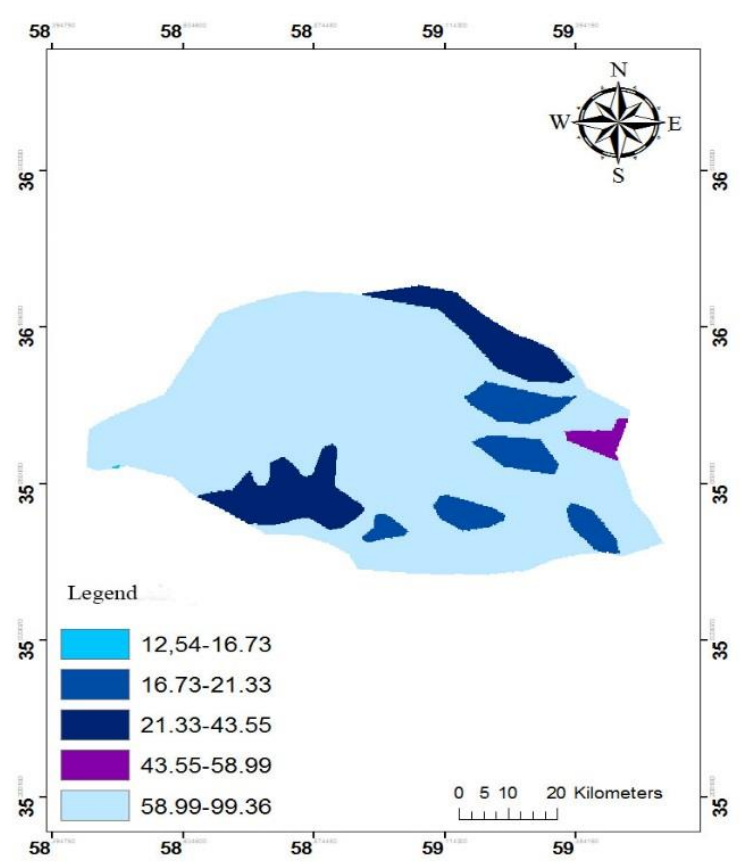

Fig. A.16: Maximum daily Runoff with a with a return period of 50 years

\subsubsection{Hydrologic soil groups (HSGs)}

To prepare the map of hydrological groups, the information on resource assessment, land capability, and soil science layers has been used. Finally, with the above three layers, the $\mathrm{CN}$ map was prepared (Figure 17). Then, using Equation 4, the maximum penetration map in the region was prepared. This layer shows the amount of rain that penetrates the ground (Figure 18). 


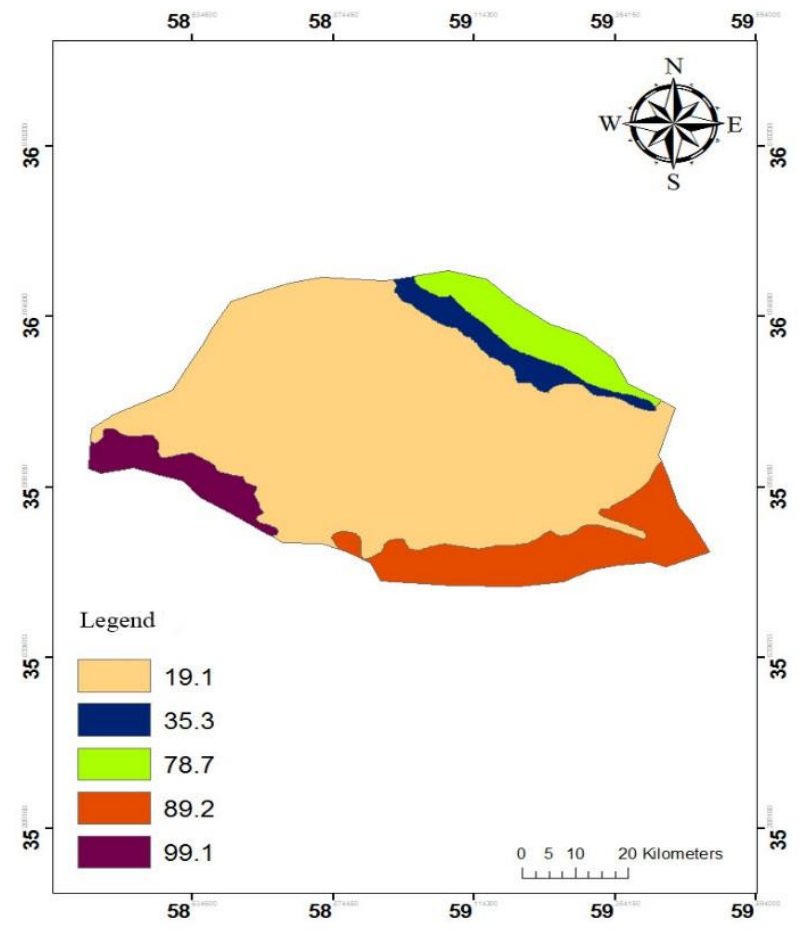

Fig. A.17: CN map of the basin

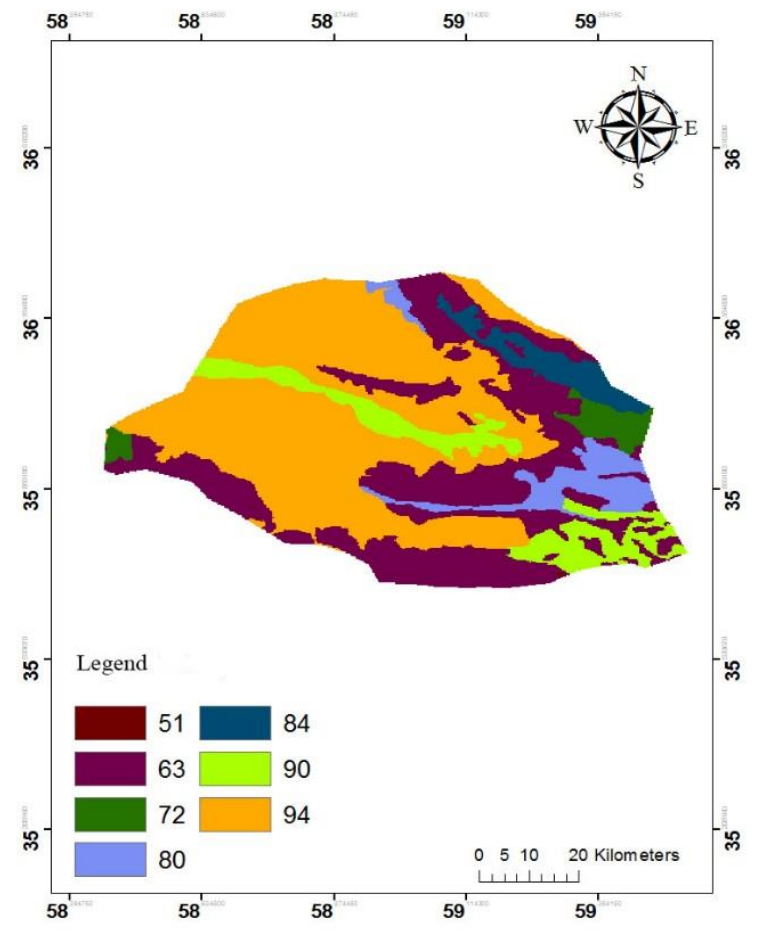

Fig. A.18: Final Infiltration Map (S)

Maps of precipitation zones with different 5, 15, 25, and 50 year return periods were prepared from data related to daily maximum precipitation. After performing the relevant tests concerning the homogeneity and adequacy of the data, the amount of precipitation for the desired return periods was prepared using the Gambling distribution Type 1. Nishabur rain-gauging station has the highest rainfall among the stations and Fadieh rain-gauging station has the lowest rainfall. After maximum precipitation was prepared for different return periods $(19,20,21$, and 22). 

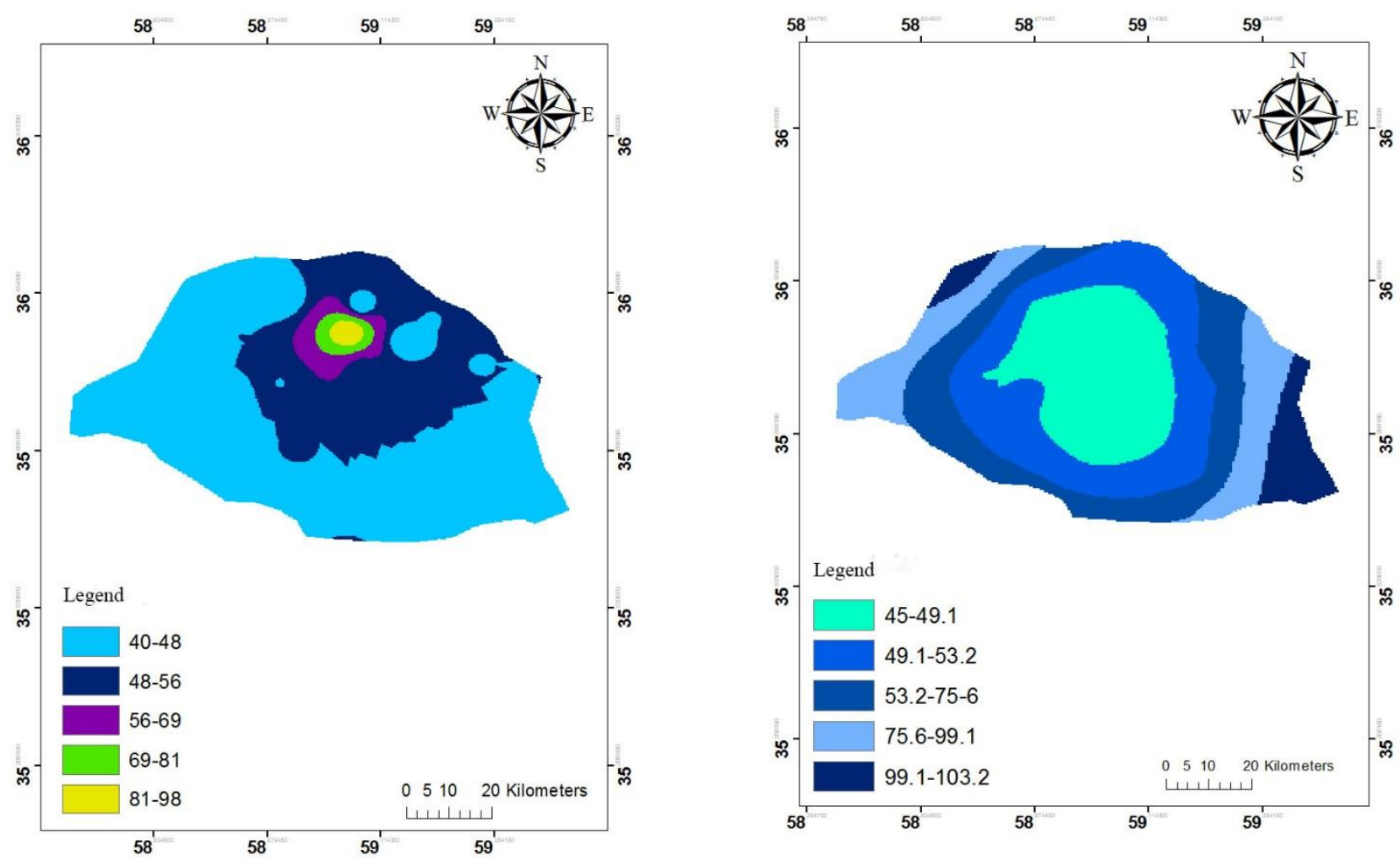

Fig. A.19: rainfall map with a 5-year return period

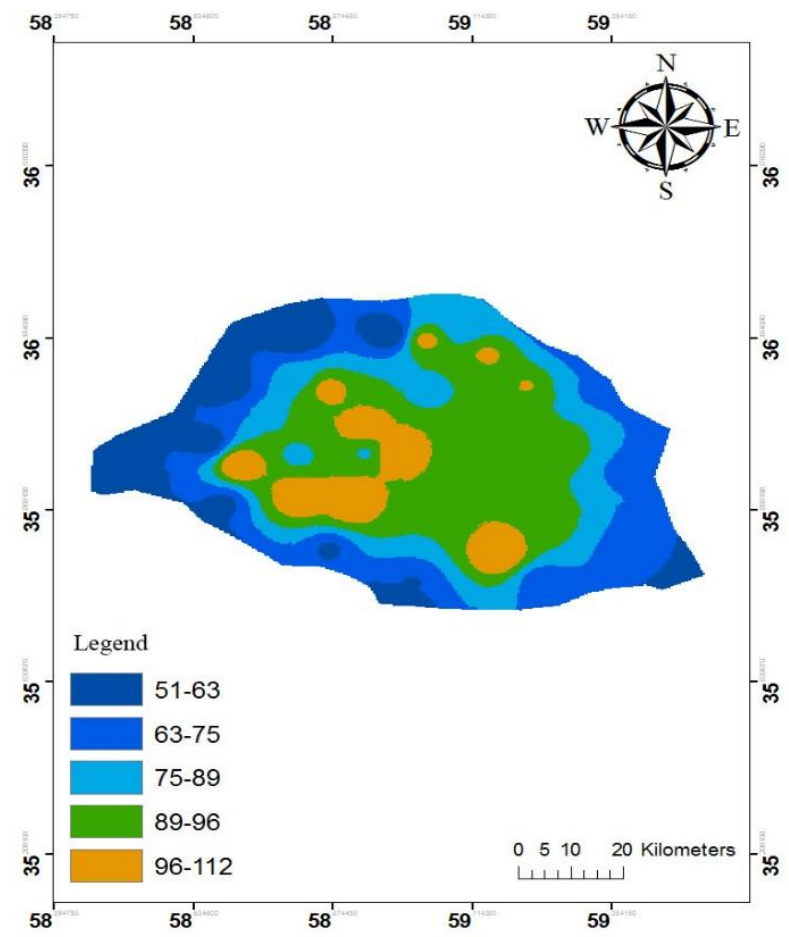

Fig. A.21: rainfall map with 25-year return period
Fig. A.20: rainfall map with a 15-year return period

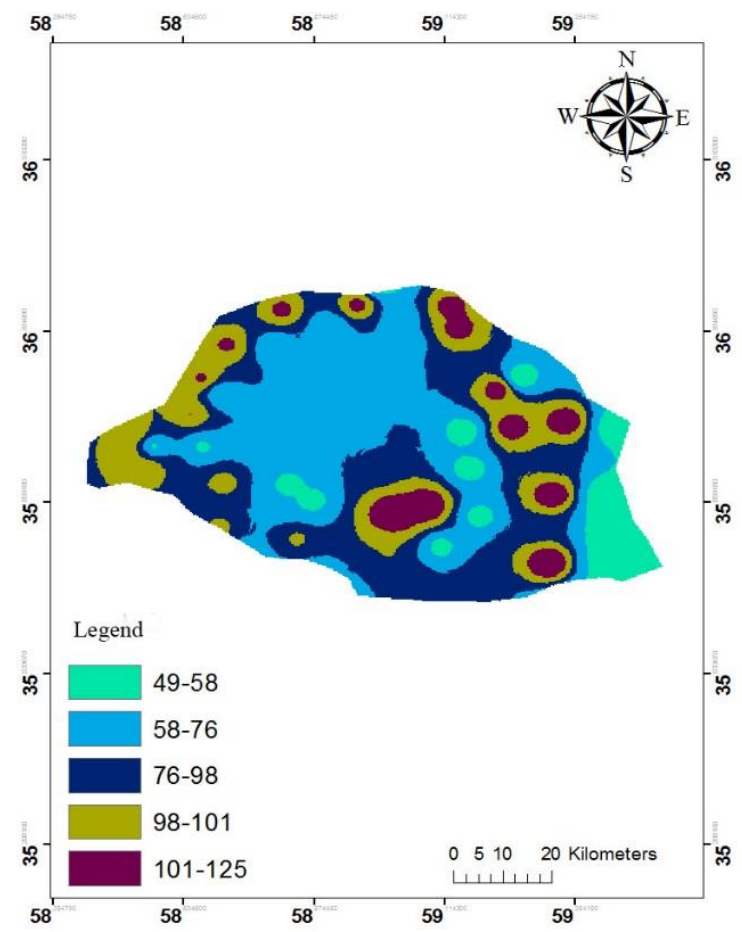

Fig. A.22: rainfall map with 50-year return period 


\subsection{Results}

Development of statistical model and determination of the weight of effective parameters in flood proneness A comparative analysis was performed between the location of past floods and environmental parameters affecting the occurrence of floods. Accordingly, the weight of each parameter was obtained. The results of logistic regression, showing the relationship between flood occurrence and effective factors in flood occurrence, are illustrated in Table 1. Data were analyzed by entering all independent and dependent variables including 21 flood positions with codes 1 and 30, and non-flood positions with code 0 into the statistical model of logistic regression and selection of Enter method.

Table A. 1: Spatial factor coefficients in the logistic regression model

\begin{tabular}{|c|c|c|c|c|c|c|c|c|c|}
\hline \multicolumn{2}{|c|}{$\% 95$ C.I. For $\mathrm{e}^{\mathrm{B}}$} & \multirow[t]{2}{*}{$\mathbf{e}^{\mathbf{B}}$} & \multirow[t]{2}{*}{$\overline{\text { sig }}$} & \multirow[t]{2}{*}{ df } & \multirow[t]{2}{*}{ Wald } & \multirow[t]{2}{*}{ S.E } & \multirow[t]{2}{*}{ B } & \multirow[t]{2}{*}{ Factor } & \multirow[t]{2}{*}{ Method } \\
\hline upper & Lower & & & & & & & & \\
\hline $1 / 076$ & $0 / 626$ & $12 / 111$ & $0 / 001$ & 1 & $10 / 213$ & $0 / 9$ & $2 / 31$ & Slope & \multirow{14}{*}{ Enter } \\
\hline $0 / 961$ & $0 / 999$ & $18 / 323$ & $0 / 05$ & 1 & $11 / 011$ & $0 / 654$ & $3 / 41$ & Lithology & \\
\hline $2 / 066$ & $0 / 728$ & $6 / 171$ & $0 / 113$ & 1 & $0 / 421$ & $0 / 001$ & $1 / 71$ & $\begin{array}{c}\text { Drainage } \\
\text { density }\end{array}$ & \\
\hline $1 / 071$ & $0 / 355$ & $0 / 153$ & $0 / 211$ & 1 & $0 / 312$ & $0 / 66$ & $-0 / 001$ & $\begin{array}{c}\text { Land } \\
\text { curvature }\end{array}$ & \\
\hline $1 / 023$ & $0 / 489$ & $6 / 322$ & $0 / 101$ & 1 & $0 / 077$ & $1 / 003$ & $1 / 22$ & Elevation & \\
\hline $0 / 961$ & $0 / 978$ & $28 / 221$ & $0 / 05$ & 1 & $13 / 251$ & $0 / 989$ & $4 / 12$ & $\begin{array}{l}\text { Distance to } \\
\text { rivers }\end{array}$ & \\
\hline $1 / 099$ & $0 / 728$ & $4 / 525$ & $0 / 271$ & 1 & $0 / 621$ & $1 / 002$ & $1 / 66$ & $\begin{array}{l}\text { Topographic } \\
\text { Wetness }\end{array}$ & \\
\hline $1 / 089$ & $0 / 711$ & $3 / 212$ & $0 / 266$ & 1 & $0 / 789$ & $0 / 001$ & $1 / 52$ & $\begin{array}{l}\text { Stream } \\
\text { Power }\end{array}$ & \\
\hline $1 / 044$ & $0 / 714$ & $12 / 101$ & $0 / 454$ & 1 & $0 / 011$ & $0 / 7$ & $0 / 1$ & Land use & \\
\hline $0 / 978$ & $0 / 933$ & $21 / 211$ & $0 / 05$ & 1 & $8 / 516$ & $0 / 921$ & $3 / 91$ & NDVI & \\
\hline $1 / 036$ & $0 / 868$ & $11 / 179$ & $0 / 001$ & 1 & $6 / 371$ & $0 / 02$ & $2 / 31$ & Rainfall & \\
\hline $1 / 714$ & $0 / 891$ & $12 / 254$ & $0 / 001$ & 1 & $4 / 459$ & $0 / 823$ & $2 / 83$ & Runoff & \\
\hline \multirow[t]{2}{*}{$1 / 623$} & $0 / 688$ & $11 / 763$ & $0 / 373$ & 1 & $0 / 853$ & $1 / 006$ & $1 / 56$ & $\begin{array}{l}\text { Hydrologic } \\
\text { soil groups }\end{array}$ & \\
\hline & & $2 / 413$ & $0 / 731$ & 1 & $0 / 058$ & $6 / 103$ & $1 / 085$ & Fixed & \\
\hline
\end{tabular}

Negative weight values for logistic regression coefficients indicate that flood occurrence is negatively correlated with independent variables. For the earth curvature factor, the weight values are negative. The greatest weight and effect on the occurrence of floods is related to the factor of distance from the waterway with a value of 4.12 . If the significance level is 0.05 , it indicates that the effective factor has a statistically significant effect on floods. The most effective factors in terms of geological significance level are the distance to waterways/rivers and NDVI. The difference in -2log likelihood (-2LL) is considered as an effective indicator of model improvement on the null model (Table 2). A minimum value of -2LL provides the best model GOF for the data and describes the reduction values up to the final iterative step. Cox/snells and negelkerkes $\mathrm{R}^{2}$ is used to measure the utility of the model. The higher $\mathrm{R}^{2}$, the better the model. Equation 9 is used to prepare the flood susceptibility map (Figure 23). 
Table A. 2: Table of logistic regression model

\begin{tabular}{|c|c|c|c|c|}
\hline Metod & Step & -2log likelihood & Cox/snells R-square & $\begin{array}{c}\text { Negelkerkes R- } \\
\text { square }\end{array}$ \\
\hline Enter & 1 & $40 / 594 \mathrm{a}$ & $0 / 701$ & $0 / 951$ \\
\hline
\end{tabular}

Equation 9:

$$
\mathrm{p}=(\text { flood susceptibility })=\frac{\mathrm{ez}}{1+\mathrm{ez}}
$$

$\mathrm{z}=2.31 *$ slope $-3.41 *$ lithology $-1.71 *$ Drainage density $-0.001 *$ curvature $-1.22 *$ altitude $-4.12 *$ DR river $-1.66 *$ TWI -1.52 SPI * $-2.87 *$ Rainfall- $0.1 *$ Land use $-3.91 *$ NDVI - Rainfall* 2/31hydrologic soil groups $* 1.56-$ runoff $* 2.83$

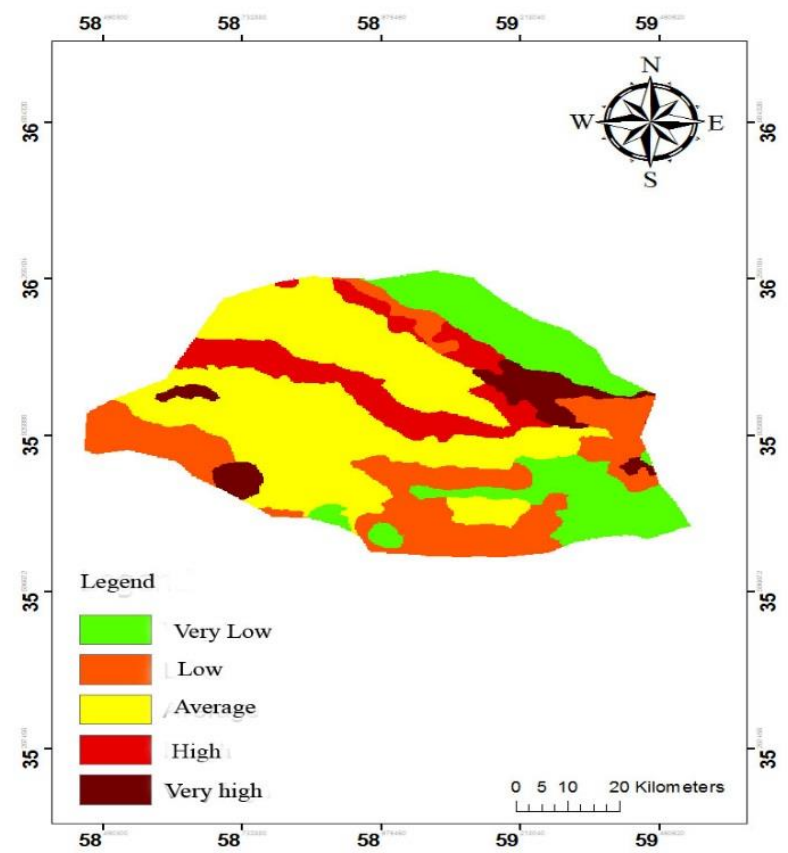

Fig. A.23: Flood susceptibility zoning map with logistic regression model

\subsubsection{Validation of the flood susceptibility map}

Validation of prepared maps is an essential step in developing and determining susceptible areas and determining their quality. In this study, the ROC curve and AUC were used for evaluation. If the AUC is 1 , it indicates the complete accuracy of the prediction. The validation or test data sets (30\% or 60\%) were used for the prediction rate. The results showed that for the prediction rate, the AUC is 0.81 (Figure 24). This method has acceptable results. 


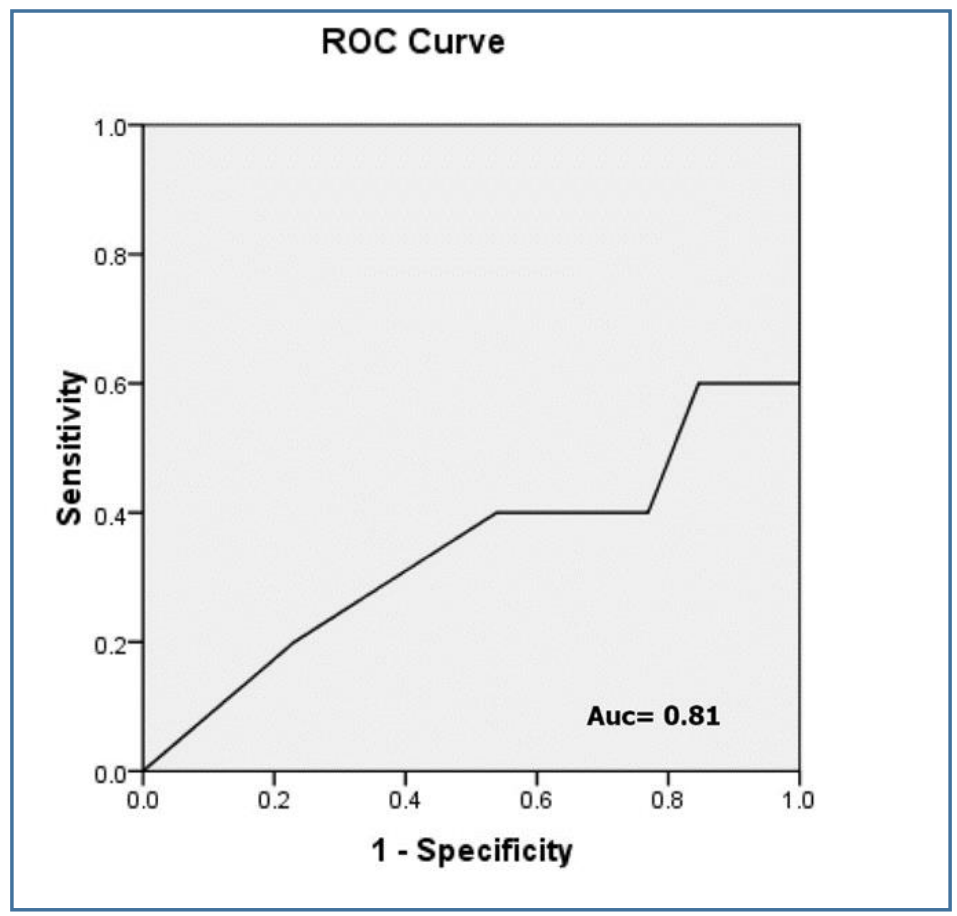

Fig. A.24: ROC curve to validate the final flood map

\subsubsection{The SCS-CN model}

For weighting the layers by the AHP method and according to expert opinions, we assigned a score from zero to one to each class. Finally, the layers were combined and a flood-prone zoning map was obtained (Equation 10). Table 3 shows the class and weight assigned to each of the factors.

Table A. 3: Scores of factors affecting the occurrence of floods

\begin{tabular}{|c|c|}
\hline $\begin{array}{c}\text { The final weight of the } \\
\text { layers }\end{array}$ & Criterion \\
\hline $0 / 033$ & Runoff \\
\hline $0 / 048$ & Hydrologic soil groups \\
\hline $0 / 151$ & Slope \\
\hline $0 / 054$ & Drainage density \\
\hline $0 / 181$ & Land curvature \\
\hline $0 / 023$ & Elevation \\
\hline $0 / 041$ & Distance to rivers \\
\hline $0 / 058$ & Topographic Wetness \\
\hline $0 / 69$ & Stream Power \\
\hline $0 / 078$ & Rainfall \\
\hline $0 / 199$ & Land use \\
\hline $0 / 191$ & NDVI \\
\hline $0 / 083$ & \\
\hline
\end{tabular}


Flooding $=0.151 *$ slope $+0.054 *$ lithology $+0.181 *$ drainage density $+0.001 *$ curvature $+0.044 *$ elevation $+0.058 *$ DR river $+0.069 *$ TWI $+0.078 *$ SPI $+0.199 *$ Rainfall $+0.191 *$ Land use $+0.083 *$ NDVI $+0.048 *$ hydrologic soil groups $+0.033 *$ runoff $+0.083 *$ NDVI

By performing the above equation on the layers, the flood-prone map with 5, 15, 25, and 50 year return periods of the basin was obtained (Figures 25, 26, 27, and 28). According to the maps, the highest proneness for flooding is in the northern and western parts of the basin, which is located at high altitudes. Investigating the layers used in flood zoning shows that these areas are more than $45^{\circ}$ in terms of the land slope. Also, these land uses are mostly rainfed with poor pastures. These conditions engender suitable conditions for floods. Concerning the eastern areas, conditions such as lower slope, denser vegetation, and low drainage density put them in the floor with moderate flood-proneness. The lowest flood-proneness in the area is concentrated at low altitudes and lower slopes, which are usually characterized by uses such as irrigated agriculture. The slope of the land in these areas is $5^{\circ}$, which causes little runoff to occur.

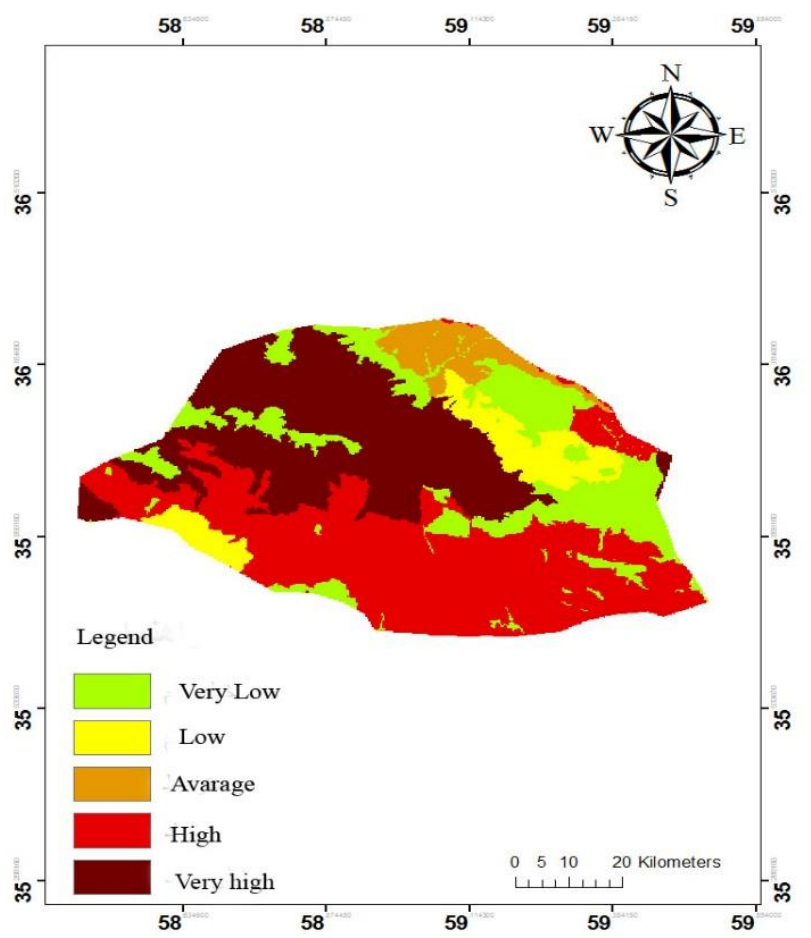

Fig. A.25: Flood potential zoning with 5 year return period return period

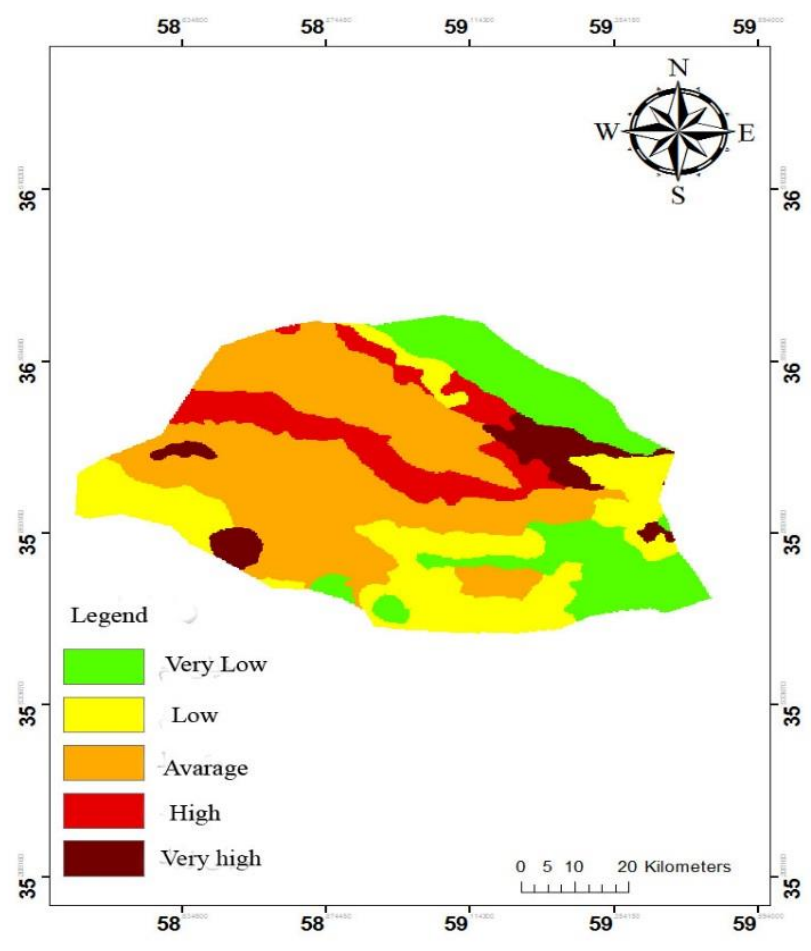

Fig. A.26: Flood potential zoning with 15 year 

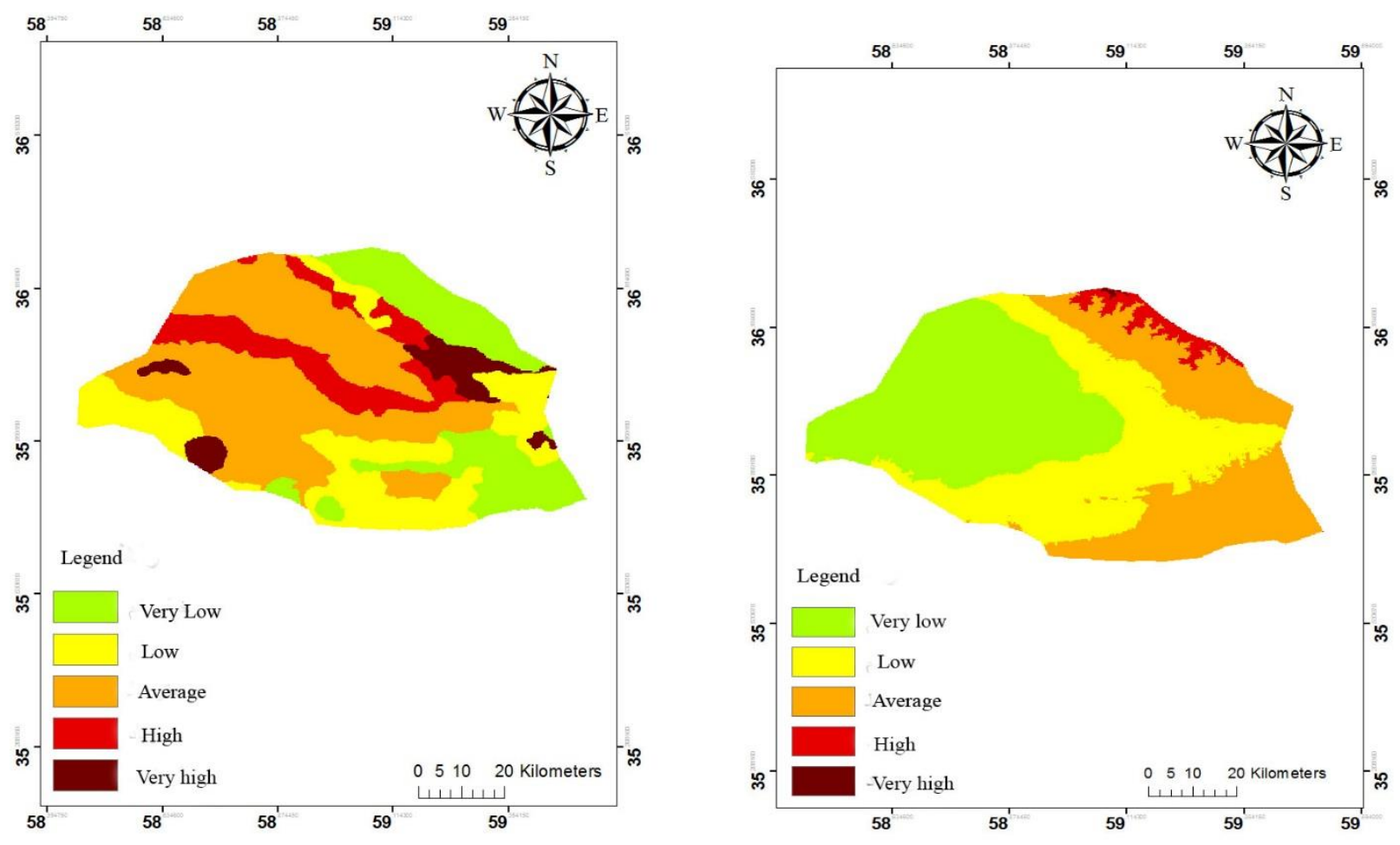

Fig. A.27: Zoning of flood potential with a 25-year return period a 50-year return period

Fig. A.28: Zoning of flood potential with

\subsection{Conclusion}

In the present study, flood risk assessment was done using thirteen runoff parameters, namely hydrologic soil groups, slope, lithology, drainage density (DD), land curvature, elevation, distance to waterways/rivers, topographic wetness index (TWI), stream power index (SPI), rainfall, land use, and NDVI. In the SCS-CN model, the infiltration rate $(\mathrm{S})$, and runoff amount $(\mathrm{Q})$ of the basin were determined. The weight of the employed layers was weighted by the AHP method and by applying the weight of the layers, a flood zoning map of the basin with different $5,15,25$, and 50 year return periods were drawn. The ROC curve and AUC were used to ensure the accuracy of the zoning map with the logistic regression model. The results showed that for the prediction rate, the AUC is $0.81 \%$, indicating that the model has an acceptable level of accuracy. The study drainage basin in the northern and western parts is located in high and very high-risk classes. The main reasons can be attributed to high altitude, steep slope, poor vegetation, high drainage density, and convex surfaces. In areas with dense vegetation, runoff is low. As a result, flood proneness decreases; therefore, they are the areas with low to moderate flood occurrences. In these areas, $\mathrm{CN}$ and Q levels are low, while $\mathrm{S}$ is high. The results indicate that the SCS-CN model has increased the speed and accuracy in preparing the flood zoning map and the predictions are very close to the existing reality. The results of investigating the parameters affecting the occurrence of floods in the study area showed that the occurrence of floods is caused by various environmental and human factors. According to the flood hazard zoning map, with the two mentioned models, appropriate management measures can be taken to reduce damage and losses caused by floods.

\section{References}


1. Asghari Saraskanrood, S., Piroozi, E., Zeinali, B. 2015. Flood risk zoning in Aq Laqanchai watershed using the Vikor model, Quantitative Geomorphological Research, 4(3), 231-245.

2. Azizah Abas, A., Hashim, M. 2014. Change detection of runoff-urban growth relationship in urbanized watershed, 8th International symposium of the Digital Earth, Conf, Series: Earth and Environmental Science, 1 012040, 1-6.

3. Baitollahpour, I., Goli Chirandeh, A., Sheibani, H., Alizadeh, H. 2018. Feasibility study of using satellite images in determining the bedrock of rivers (Case study: Gabrik River), $11^{\text {th }}$ International Seminar on River Engineering, 8.

4. Esfandiari Darabad, F., Rahimi, M., Pour Mortezaieh, Gh.R. 2019. Flood zonation of Agerloo Cay Basin using the L-THIA method and fuzzy logic, Quantitative Geomorphological Research, 8(2), 155-171.

5. Falah, F., Rahmati, O., Rostami, M., Ahmadisharaf, E., Daliakopoulos, N., Pourghasemi, H. R. 2019. Artificial neural networks for flood susceptibility mapping in data-scarce urban areas, Spatial Modeling in GIS and R for Earth and Environmental Sciences, Elsevier, 14, 323-336 .

6. Fanni, Z., Gheshmi, S. M. R. 2017. Spatial zoning and analysis of the four environmental hazards of landslides, floods, earthquakes and subsidence (Case study: 22 districts of Tehran), Journal of Geographical Data (SEPEHR), 27(4), 76-89.

7. Green, C., Diepernk, G., EK, K., Hegger, D., Pettersson, M., Priest, S., Tapsell, S. 2014. Flood risk management in Europe: the flood problem and interventions, Star flood, 1- 250.

8. Homser, D.W and lemeshow, s. 2000. Applied logistic regression, second ed. John wiley a sons inc, new York.

9. Jia, J., Wang, X., A. M, Hersi, N., Zhao, W, Liu, Y. 2019. Flood-risk zoning based on analytic hierarchy process and fuzzy variable set theory, Natural Hazards Review, 20(3), 2-8.

10. Lee, s and Pradhan, B. 2007. Landslide hazard mapping at Selangor, Malaysia using frequency ratio and logistic regression models, land slides , 4, 33, 33-41.

11. Lee, S. 2004. Application of likelihood ratio and logistic regression models to landslide susceptibility mapping using GIS. Environmental Management, 34(2), 223-232.

12. Leizadeh Gorji, Gh.R., Roustaei, Sh., Mousavi, R. 2017. Preparation of flood zonation map of Nekarud watershed using SCS-CN and RS/GIS models, Journal of Quantitative Geomorphological Research, 6(1), 108-118.

13. Mir Ghasemi, S.H., Banjad, H., Farid Hosseini, A.A. 2019. Evaluation of the effect of land-use change on riverbeds on flood rate and intensity (Case study: Ardak River), Geographical studies of arid regions, 9(36), 44-61.

14. Mohtar WHM, W., Abdullah, J., Abdul Maulud, KN., Muhammad, NS. 2020. Urban flash flood index based on historical rainfall events, Sustainable Cities and Society , doi: https://doi.org/10.1016/j.scs.2020.102088.

15. Mollazehi, A., Pudineh, M.R., Khosravi, M., Armesh, M., Dehvari, A.A. 2020. PoteAssessment of the Potential Flood Risk in Sarbaz Drainage Basin, Journal of Applied Research in Geographical Sciences, Vol 20(58), 241-260.

16.Pourghasemi, HR., Moradi, HR., Aghda, SMF., Gokceoglu, C., Pradhan, B. 2014. GIS-based landslide susceptibility mapping with probabilistic likelihood ratio and spatial multi-criteria evaluation models (North of Tehran, Iran). Arab J Geosci. 7(5):1857-1878

17. Pratyasha, J., and Prachi, ch.(2016). Assessment of Cartosat-1 DEM for Modeling Floods in Data Scarce Regions, Water Resour Manage DOI 10.1007/s11269-016-1226-9

18. Rahimzadeh, O., Bahremand, A., Noura, N., and Mukolwe, M. 2019, Evaluating flood extent mapping of two hydraulic models, 1D HEC-RAS and 2D LISFLOOD-FP in comparison with 
aerial imagery observations in Gorgan flood plain,/ Iran, Natural Resource Modeling, 12p. DOI: $10.1111 / \mathrm{nrm} .12214$.

19. Razavi Termeh, S.V \& Malek, M.R. 2017. Preparation of flood susceptibility mapping using an ensemble of frequency ratio and adaptive neuro-fuzzy inference system models (Case study: Jahrom Township), Journal of Geomatics Science and Technology, 8(3), 1-15.

20. Reisenbüchler, M., Duc Bui, M., Skublics, D., Rutschmann, P. 2019. An integrated approach for investigating the correlation between floods and river morphology: A case study of the Saalach River, Germany, journal Science of the Total Environment, 647, 814-826

21. Roustaei, Sh., Ayaseh, F., Rezaei Moghadam, M.H. 2020. Quasi 2 dimensional simulation of Lighvan River flood flow with emphasis on floodplain using MIKE11 technique, Quantitative Geomorphological Research, 9(1), 21-28.

22. Sharifi Pichun, M., \& Pornoon, F. 2018. Spatial evaluation and analysis of flooding of Qara Sood river using fuzzy logic in GIS, Journal of Natural Environment Hazards, 7(15), 17-30.

23. Shirzadi, A, saro, L,joo, o.H, chapi, k. 2012. A gis based logistic regression model in roak fall susepitbility mapping along a mountainous road : salavat abad case study, Kurdistan , iran, Natural hazard , 64, 1639- 1656.

24. Talebi, A., Abyari, I., Parvizi, S. 2019. Prioritization of Sub-Watersheds from Flooding Viewpoint Using the SWAT Model (Arazkoose Watershed, Golestan Province), Journal of Water and Soil Sciences, Agricultural Science and Technology and Natural Resources, 23, Special Issue on Flood and Soil Erosion, 409-419.

25. Wang, L. J., Guo, M., Sawada, K., Lin, J., Zhang, J. 2015. Landslide susceptibility mapping in Mizunami City, Japan: A comparison between logistic regression bivariate statistical analysis and multivariate adaptive regression spline models, Catena, 135, 271-282.

26. Yari, A., Ardelan, A., taghizadeha, A., Zarezadeh, Y., Soufi Boubakran, M., Bidarpoor, F., Rahimiforoushan, A. 2019. Underlying factors affecting death due to flood in Iran: A qualitative content analysis, International Journal of Disaster Risk Reduction, 40, 1-10.

27. Zhongqian, T., Zhang, H., Shanzhen, Yi., Yangfan, X. 2018. Assessment of flood susceptible areas using spatially explicit, probabilistic multi-criteria decision analysis, Journal of Hydrology, doi: https://doi.org/10.1016/ j.jhydrol.2018.01.033. 